\title{
Experimento com variedades de soja do Programa de Colaboração INPA- INTSOY, realizado na várzea da ilha da Paciência, rio Solimōes, 1976-1977
}

\author{
Fazal Rahman ( $\left.{ }^{*}\right)$
}

\section{Resumo}

O presente experimento foi realizado em colaboração com o Programa Internacional de Soja (INTSOY), dos E.U.A., dando continuidade à procura de novas e diversificadas fontes de germoplasma adaptáveis à Amazônia. O plantio foi realizado tardiamente na época de cultivo da várzea. Embora experimentos dessa natureza sejam indesejáveis, se vistos do ponto de vista de um produtor, fornecem informações valiosas para o melhorista de plantas. Devido ao fato dos genótipos serem submetidos às condições naturais mais severas e desfavoráveis, os tipos resistentes são os que sobrevivem e são selecionados e usados nos programas gerais de melhoramento e produção. Hill, uma nova variedade introduzida, produziu $1.265 \mathrm{~kg}$ por hectare de sementes de alta qualidacie em 74,5 dias e foi resistente a doenças. Esta variedade pode ser importante para várzeas, onde há necessidade de cultivares com produção relativamente alta e curto período de maturação, para que a colheita possa ser feita mecanicamente ainda durante a estação seca. Manaus-1 (uma linhagem do INPA) produziu a maior colheita, de $2.217 \mathrm{~kg}$ por hectare, seguida pela variedade Júpiter com $1.373 \mathrm{~kg}$ por hectare. Ambas variedades devem ser plantadas mais cedo e testadas sob condições mais favoráveis, para que possam ser melhor avaliadas

\section{INTRODUÇÃo}

O Programa Internacional de Soja (INTSOY) organizou o "International Soybean Variety Evaluation Experiments" (ISVEX), em colaboração com a "United States Agency for International Development", durante 1973. Estas séries de experimentos têm sido bastante úteis na identificação de novas áreas com potencial para a produção de um dos cultivos mais nutritivos que se conhece. Em 1974 o ISVEX foi requisitado por 136 localidades em 60 países (Whigham, 1976). Em 1975 o INPA iniciou contatos com o INTSOY a fim de participar desse empreendimento internacional.
Desde então têm sido realizados diversos experimentos conjuntos na várzea e na terra firme da Amazônia. Em 1976, assim que se constatou que a produção de certos genótipos (Rahman, 1977) de soja, particularmente adaptados às várzeas, é altamente viável, o INPA continuou a introduzir e testar diversas fontes de germoplasma em diferentes áreas da Amazônia. A criação e funcionamento de um banco de germoplasma na Amazônia é da mais alta importância, neste estágio, para que os melhoristas de plantas possam criar novas combinações de genótipos adaptados aos diferentes ambientes amazônicos. O presente experimento tem esse objetivo.

\section{MATERIAIS E MÉTODOS}

Quinze variedades provenientes do INTSOY e uma linhagem do INPA, designada como Manaus- 1 , foram plantadas segundo o modelo experimental de blocos totalmente casualizados, nos quais cada variedade foi replicada 4 vezes em canteiros de 4 linhas. O comprimento das linhas foi de 5 metros. A distância entre as linhas foi de $60 \mathrm{~cm}$ e entre as plantas de $5 \mathrm{~cm}$. Somente as duas linhas centrais foram utilizadas para coleta de dados, exceto no caso de nodulação em que 10 plantas foram arrancadas das duas linhas externas dos canteiros em duas datas diferentes: na época de florescimento e três semanas mais tarde.

Os dados coletados se referem à produção. número de dias requeridos para $50 \%$ de flores. cimento e $95 \%$ de maturação, número de nódulos e peso seco dos nódulos (secagem feita em forno a $70^{\circ} \mathrm{C}$ por 24 horas) em duas datas diferentes, altura da planta, acabamento, deiscência, número de plantas colhidas, número de vagens por planta, peso de 100 sementes, qualidade de sementes e índice de doença.

(*) - Instituto Nacional de Pesquisas da Amazônia, Manaus. 
As análises de solo realizadas no labora tório da EMBRAPA indicaram um pH de 4,8 e uma proporção de $0,17 \% \mathrm{~N}, 1,4 \% \mathrm{C}, 17 \mathrm{ppm} \mathrm{P}$, 18,6 me $\%$ de $\mathrm{Ca}+\mathrm{Mg}$ e $1,3 \mathrm{me} \%$ de $\mathrm{Al}$. Duas toneladas de calcário e $25 \mathrm{Kg}$ de $\mathrm{N}$, de $\mathrm{P}$ e de $\mathrm{K}$ foram aplicados ao solo de cada hectare. Devido ao problema da disponibilidade de áreas experimentais, o intervalo entre a aplicação do calcário e o plantio foi muito curto, i.e., de 7 dias. O Rhizobium japonicum (granular) foi adicionado nas fileiras imediatamente após o plantio das sementes. O experimento foi plantado em $23 / 11 / 76$. As sementes foram plantadas, colhidas e debulhadas manualmente. Os inseticidas Malathion e Azodrin foram aplicados de tempos em tempos para controle de alguns insetos.
As variedades incluídas no experimento foram: Manaus-1 (linhagem de controle); Júpiter, Hill, Forrest, Williams, Ranson, Woodworth, Bragg, Davis, Pickett 71, Bossier, Essex, Clark 63, Pelicano Melhorado, Calland, Cobb.

Os dados foram analizados em computador para análise de variância e testes de correlação. O teste da diferença mínima significativa (LSD) foi empregado para comparaçōes de níveis de significância das diferenças entre as médias. A precipitação total recebida durante o periodo de crescimento foi de $952,9 \mathrm{~mm}$.

\section{RESULtados E DISCUSSÃO}

A Tabela I contém os dados sobre produção de sementes, número de dias para florescimento e maturidade, número de nódulos, pe-

TABELA 1 - Resultados dos experimentos INPA INTSOY na ilha da Paciência (várzea do rio Solimões). Colheita (em quilos por hectare), n. ${ }^{\circ}$ de dias até o florescimento, n..$^{\circ}$ de dias até a maturidade, n.॰ de nódulos 1 (na época de florescimento), $n 0^{\circ}$ de dias até a maturidade, $n .^{\circ}$ de nódulos 1 (na época de florescimento), n. ${ }^{\circ}$ de nódulos 2 (três semanas após o florescimento), peso dos nódulos 1 , peso dos nódulos 2 (correspondendo às datas em que foi contado o número de nódulos), altura da planta, acamamento, deiscência, n. de plantas colhidas, n..$^{\circ}$ de vagens por planta, peso de 100 sementes, qualidade das sementes e indice de doença dados de 16 variedades de soja plantadas na ilha da Paciência em 23 de novembro de 1976.

\begin{tabular}{|c|c|c|c|c|c|c|c|c|c|c|}
\hline VARIEDADE & 这 & 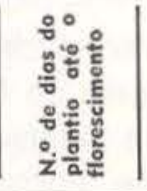 & 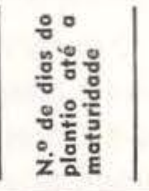 & 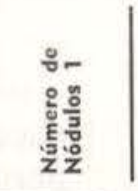 & 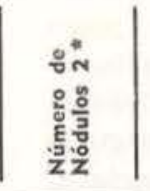 & 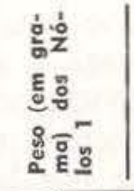 & 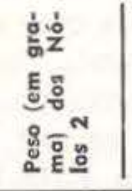 & 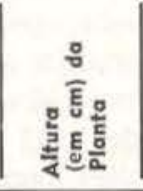 & 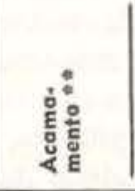 & 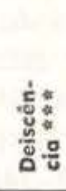 \\
\hline Manaus-1 & 2217 & 50.00 & 119.00 & 69.00 & 106.00 & 0.77 & 1.18 & 95.1 & 3.25 & 1 \\
\hline Júpiter & 1373 & 38.00 & 110.50 & 79.25 & 52.50 & 0.55 & 0.70 & 66.5 & 3.00 & 1 \\
\hline Hill & 1265 & 26.75 & 74.50 & 37.25 & 36.25 & 0.63 & 0.67 & 36.2 & 1.00 & 1 \\
\hline Forrest & 1101 & 26.00 & 87.00 & 39.75 & 66.00 & 0.60 & 1.10 & 38.8 & 1.00 & 1 \\
\hline Williams & 937 & 25.25 & 85.25 & 77.50 & 44.00 & 1.08 & 0.88 & 73.3 & 1.50 & 1 \\
\hline Ransom & 817 & 26.75 & 90.50 & 57.25 & 39.75 & 0.65 & 0.67 & 35.3 & 1.00 & 1 \\
\hline Woodworth & 776 & 23.00 & 75.00 & 41.75 & 34.75 & 0.78 & 0.63 & 65.4 & 1.00 & 1 \\
\hline Bagg & 745 & 26.00 & 89.50 & 62.50 & 66.50 & 0.80 & 0.80 & 36.8 & 1.00 & 1 \\
\hline Davis & 728 & 26.00 & 88.75 & 40.75 & 46.25 & 0.90 & 1.05 & 34.7 & 1.00 & 1 \\
\hline Picketti 71 & 641 & 26.00 & 87.75 & 31.75 & 46.25 & 0.50 & 0.83 & 28.3 & 1.00 & 1 \\
\hline Bossier & 559 & 25.25 & 90.75 & 45.25 & 45.25 & 0.70 & 0.55 & 33.1 & 1.00 & 1 \\
\hline Essex & 531 & 23.75 & 87.00 & 81.75 & 42.50 & 0.82 & 0.80 & 29.7 & 1.00 & 1 \\
\hline Clark 63 & 477 & 23.75 & 86.00 & 72.25 & 33.50 & 0.95 & 0.60 & 72.0 & 1.50 & 1 \\
\hline Pelicano Melhorado & 321 & 33.00 & 98.25 & 34.25 & 54.50 & 0.65 & 0.90 & 90.4 & 2.00 & 1 \\
\hline Calland & 272 & 23.75 & 84.50 & 56.50 & 42.00 & 0.93 & 0.83 & 74.0 & 1.50 & 1 \\
\hline $\mathrm{Cobb}$ & 231 & 27.75 & 93.75 & 32.50 & 53.00 & 0.55 & 0.60 & 39.8 & 1.00 & 1 \\
\hline C.v. & $61.93 \%$ & $4.08 \%$ & $3.27 \%$ & $50.96 \%$ & $54.07 \%$ & $39.22 \%$ & $37.86 \%$ & $9.84 \%$ & $18.02 \%$ & 0 \\
\hline $\begin{array}{l}5 \% \text { LSD - média } \\
\text { de variedade }\end{array}$ & 716 & 1.64 & 4.22 & NS & NS & NS & NS & 7.4 & 0.36 & 0 \\
\hline
\end{tabular}

- Dados sobre nóduics baseados em 10 plantas.

*. Acamamento $-1=$ năo acama, $2=$ acama muito pouco, $3=$ acama moderadamente, $4=$ acamamento de 50 a $80 \%$ đas plantas, $5=$ praticamente todas as plantos acamam.

*.. Deiscência $-1=$ năo deiscende. 


\begin{tabular}{|c|c|c|c|c|c|c|}
\hline \multirow{2}{*}{ Variedade } & \multirow{2}{*}{$\begin{array}{l}\text { Número de } \\
\text { plantas } \\
\text { colhidas }\end{array}$} & \multirow{2}{*}{$\begin{array}{l}\text { Número de } \\
\text { vagens por } \\
\text { planta }\end{array}$} & \multirow{2}{*}{$\begin{array}{c}\text { Peso de } 100 \\
\text { sementes } \\
\text { em gramas }\end{array}$} & \multirow{2}{*}{$\begin{array}{c}\text { Qualidade } \\
\text { da } \\
\text { semente + }\end{array}$} & \multicolumn{2}{|c|}{ Indice de Doenças ++} \\
\hline & & & & & $\left|\begin{array}{c}\text { Vírus Mosáico } \\
\text { comum da } \\
\text { Soja (SMV) }\end{array}\right|$ & $\begin{array}{l}\text { Mancha } \\
\text { Púrpura }\end{array}$ \\
\hline Manaus-1 & 133.5 & 119.4 & 14.5 & 3.00 & 3.00 & 1.75 \\
\hline Júpiter & 104.3 & 51.4 & 21.3 & 2.75 & 2.25 & 1.50 \\
\hline Hill & 140.8 & 36.5 & 16.0 & 1.75 & 1.25 & 1.25 \\
\hline Forrest & 142.3 & 48.0 & 17.1 & 3.00 & 1.00 & 3.75 \\
\hline Williams & 139.8 & 39.5 & 20.1 & 2.25 & 2.00 & 2.00 \\
\hline Ransom & 143.8 & 36.3 & 22.0 & 3.75 & 1.25 & 3.50 \\
\hline Woodworth & 138.8 & 43.6 & 16.6 & 2.50 & 1.00 & 1.50 \\
\hline Bragg & 136.5 & 35.0 & 21.1 & 3.25 & 1.00 & 4.75 \\
\hline Davis & 147.3 & 40.7 & 19.9 & 3.25 & 1.00 & 3.00 \\
\hline Pickett 71 & 135.3 & 33.1 & 19.8 & 2.50 & 1.00 & 4.00 \\
\hline Bossier & 140.8 & 40.3 & 20.7 & 3.75 & 1.00 & 4.25 \\
\hline Essex & 136.3 & 33.4 & 19.6 & 3.25 & 1.00 & 4.50 \\
\hline Clark 63 & 144.3 & 37.9 & 19.4 & 2.75 & 1.00 & 1.75 \\
\hline Pelicano Melhorado & 115.0 & 52.7 & 16.5 & 2.25 & 2.00 & 1.00 \\
\hline Calland & 146.3 & 39.2 & 20.0 & 3.00 & 1.00 & 2.00 \\
\hline $\mathrm{Cobb}$ & 135.8 & 43.4 & 18.8 & 3.25 & 1.25 & 3.25 \\
\hline C.V. & $8.86 \%$ & $16.93 \%$ & $8.21 \%$ & $22.75 \%$ & & \\
\hline $\begin{array}{l}\mathbf{5} \% \text { LSD - média } \\
\text { de variedade }\end{array}$ & 17.2 & 11.0 & 2.2 & 0.94 & & \\
\hline
\end{tabular}

+ - Qualidade das sementes $-1=$ excelente, $2=$ bom, $3=$ regular, $4=$ pobre, $5=$ muito pobre.

++ - Indice de doenças $-1=$ nenhum sintoma, $\overline{2}=$ sinto mas leves, algumas plantas afetadas, $3=$ sintomas moderados, um número considerável de plantos afetadas, $4=$ sintomas severos na maioria das plantos, $5=$ sintomas muito severos em quase todas as plantas ou sementes.

so seco dos nódulos, altura da planta, acamamento, deiscência, número de plantas colhidas das duas fileiras centrais, número de vagens por planta (média de 10 plantas), peso de 100 sementes, qualidade das sementes e índice de doença. As Tabelas 2 e 3 mostram 03 resultados das correlações e análises de variância.

Manaus-1, a linhagem local de controle, produziu a maior colheita de sementes, i.e., $2.217 \mathrm{~kg}$ por hectare, que representa uma diferença estatisticamente significativa em relação à produtividade das outras variedades. A variedade Manaus-1 é o resultado do cruzamento entre as variedades Oriente e F742 - PI341,257 , realizado no INPA. Júpiter foi uma variedade que também produziu muito, com $1.373 \mathrm{~kg}$ por hectare, seguida por Hill, Forrest e Williams com 1.265, 1.101 e 937 kg por hec- tare, respectivamente. Cobb foi a variedade que menos produziu, com $231 \mathrm{~kg}$ por hectare, e também teve a menor produção em um experimento prévio realizado na várzea do Caldeirão (Rahman, 1977). Pelicano Melhorado, uma variedade que produziu $2.114 \mathrm{~kg}$ por hectare no Caldeirão, produziu apenas $321 \mathrm{~kg}$ por hectare no presente experimento. Júpiter foi a variedade de maior produçāo em Caldeirão, com $4.588 \mathrm{~kg}$ por hectare (Rahman, 1977).

A baixa produtividade das variedades no presente experimento foi causada pelos seguintes fatores:

(i) Atraso no plantio, agravado por problemas de chuvas excessivas e incidência de doenças durante estágios critícos do crescimento da planta;

(ii) Fertilidade relativamente baixa do solo da ilha da Paciência, provavelmente causada 
TABELA $2-$ Correlações $(+$ Prob.$=0.05++$ Prob. $=.01)$

\begin{tabular}{|c|c|c|c|c|c|c|c|c|c|c|c|c|c|}
\hline & $\begin{array}{l}\text { colheita } \\
\mathrm{kg} / \mathrm{ha}\end{array}$ & $\begin{array}{c}n 0^{\circ} \text { de dias } \\
\text { para flo- } \\
\text { rescimento }\end{array}$ & $\begin{array}{c}\text { n.o de dias } \\
\text { para ma- } \\
\text { turidade }\end{array}$ & $\begin{array}{c}\mathrm{n} \cdot{ }^{0} \text { de } \\
\text { nódulos } \\
1\end{array}$ & $\begin{array}{c}n \cdot 0 \text { de } \\
\text { nódulos } \\
2\end{array}$ & $\begin{array}{c}\text { peso pos } \\
\text { nódulos } \\
1\end{array}$ & $\begin{array}{c}\text { peso pos } \\
\text { nódulos } \\
2\end{array}$ & $\begin{array}{c}\text { altura } \\
\text { da } \\
\text { planta }\end{array}$ & $\begin{array}{l}\text { acama- } \\
\text { mento }\end{array}$ & $\begin{array}{l}\text { plantas } \\
\text { colhidas }\end{array}$ & $\begin{array}{l}\text { vagem } \\
\text { por } \\
\text { planta }\end{array}$ & $\begin{array}{c}\text { peso } \\
\text { de } 100 \\
\text { sementes }\end{array}$ & $\begin{array}{l}\text { qualidade } \\
\text { das } \\
\text { sementes }\end{array}$ \\
\hline Colheita kg/ha & 1.00 & $0.53++$ & $0.36++$ & 0.08 & 0.23 & -0.04 & 0.15 & 0.18 & $0.44++$ & -0.05 & $0.51++$ & $-0.32+$ & -0.20 \\
\hline $\begin{array}{l}\text { n. } \\
\text { mento de dias para floresci- }\end{array}$ & $0.53++$ & 1.00 & $0.86++$ & 0.14 & $0.44++$ & -0.11 & 0.24 & $0.54++$ & $0.84++$ & $-0.37++$ & $0.85++$ & $-0.35++$ & -0.04 \\
\hline n. ${ }^{\circ}$ de dias para maturidade & $0.36++$ & $0.86++$ & 1.00 & 0.21 & $0.47++$ & -0.13 & 0.19 & $0.44++$ & $0.79++$ & $-0.42++$ & $0.70++$ & -0.05 & 0.18 \\
\hline n.o de nódulos 1 & 0.8 & 0.14 & 0.21 & 1.00 & -0.02 & $0.49++$ & -0.09 & 0.17 & $0.26+$ & -0.10 & 0.13 & 0.22 & 0.09 \\
\hline n.o de nódulos 2 & 0.23 & $0.44++$ & $0.47++$ & -0.02 & 1.00 & 0.05 & $0.57++$ & 0.19 & $0.38++$ & -0.10 & $0.46++$ & -0.01 & 0.12 \\
\hline peso dos nódulos 1 & -0.04 & -0.11 & -0.13 & $0.49++$ & 0.05 & 1.00 & 0.07 & 0.15 & -0.07 & 0.23 & -0.02 & 0.10 & 0.14 \\
\hline peso dos nódulos 2 & 0.15 & 0.24 & 0.19 & -0.09 & $0.57++$ & 0.07 & 1.00 & 0.16 & $0.26+$ & 0.05 & 0.23 & -0.04 & -0.01 \\
\hline Altura da planta & 0.18 & $0.54++$ & $0.44++$ & 0.17 & 0.19 & 0.15 & 0.16 & 1.00 & $0.71++$ & $-0.29+$ & $0.57++$ & $-0.33++$ & -0.23 \\
\hline Acamamento & $0.44++$ & $0.84++$ & $0.79++$ & $0.26+$ & $0.38++$ & -0.07 & $0.26+$ & $0.71++$ & 1.00 & $-0.44++$ & $0.71++$ & -0.19 & -0.14 \\
\hline Plantas colhidas & -0.05 & $-0.37++$ & $-0.42++$ & -0.10 & -0.10 & 0.23 & 0.05 & $-0.29+$ & $-0.44++$ & 1.00 & -0.15 & -0.03 & 0.16 \\
\hline Vagens por planta & $0.51++$ & $0.85++$ & $0.70++$ & 0.13 & $0.46++$ & -0.02 & 0.23 & $0.57++$ & $0.71++$ & -0.15 & 1.00 & $-0.53++$ & 0.03 \\
\hline Peso de 100 sementes & $-0.32+$ & $-0.35++$ & -0.05 & 0.22 & -0.01 & 0.10 & -0.04 & $-0.33++$ & -0.19 & -0.03 & $-0.53++$ & 1.00 & $0.32++$ \\
\hline Qualidade das sementes & -0.20 & -0.04 & 0.18 & 0.09 & 0.12 & 0.14 & -0.01 & -0.23 & -0.14 & 0.16 & 0.03 & $0.32++1$ & 1.00 \\
\hline
\end{tabular}


pela rapidez da correnteza em comparação com as margens do rio, o que dificulta o deposito de sedimentos ricos no solo;

(iii) Nodulação pobre;

(iv) Intervalo curto entre a aplicação de calcário e o plantio, sem tempo suficiente para a adaptação do $\mathrm{pH}$.

Nos experimentos realizados pelo INTSOY em 1974, a variedade Júpiter teve altas produções em certas localidades, como por exemplo na Venezuela, onde produziu $5.465 \mathrm{~kg}$ por hectare. Uma linhagem resultante do cruzamento entre as variedades Júpiter e F67-1533 produziu $4.140 \mathrm{~kg} / \mathrm{ha}$., mais que Júpiter, com $3.676 \mathrm{~kg} / \mathrm{ha}$, na Guiana. Na Zona 1 (37 localidades situadas a menos de $500 \mathrm{~m}$ de altitude e $10^{\circ}$ de latitude, entre o Equador) as locali- dades sul-americanas alcançaram a maior produção média da região com $2.435 \mathrm{~kg} / \mathrm{ha}$ em 8 sítios. A maior produção média dos cultivares foi alcançada pela variedade Júpiter com 3.359 $\mathrm{kg} / \mathrm{ha}$ (Whigham, 1976). Todos estes resultados são consistentes com os experimentos que o INPA realizou utilizando a variedade Júpiter. Nos experimentos realizados pelo IITA também foi constatado que Júpiter é um dos cultivares mais produtivos, (Nangju et al., 1974 e 1975). As variedades requerem de 23 a 50 dias para florescer e de 74,5 a 119 dias para maturar. Manaus-1, Júpiter e Hill requizeram 50,38 e 27 dias para florir e $119,110,5$ e 74,5 dias para maturar, respectivamente. Muitas das diferenças foram estatisticamente significativas, conforme demonstrado pelos valores LSD na Tabela 1.

TABELA 3 - Resultados da análise de variância para cada variável

\begin{tabular}{|c|c|c|c|c|c|c|c|}
\hline $\begin{array}{c}\text { Nome da } \\
\text { variável }\end{array}$ & Total SS & Réplica SS & $\begin{array}{l}\text { Variedade } \\
\text { MS }\end{array}$ & $\begin{array}{l}\text { Erro } \\
\text { MS }\end{array}$ & $\begin{array}{c}\text { Valor } \\
\text { F }\end{array}$ & CV & LSD \\
\hline $\begin{array}{l}\text { Graus de } \\
\text { liberdade }\end{array}$ & 63 & 3 & 15 & 45 & & & \\
\hline Colheita $\mathrm{kg} / \mathrm{ha}$ & 27319215.77303 & 0.79688 & 1003184.32719 & 252825.22234 & $3.97+$ & 61.93 & 716.12 \\
\hline $\begin{array}{l}\mathrm{N}:{ }^{\circ} \text { de dias para } \\
\text { florescimento }\end{array}$ & 2947.75 & 1.95797 & 192.51667 & 1.325 & $145.30+$ & 4.03 & 1.64 \\
\hline $\begin{array}{l}\text { N. }{ }^{\circ} \text { de dias para } \\
\text { maturidade }\end{array}$ & 7994.00 & 163.24422 & 506.43333 & 8.76944 & $57.75+$ & 3.27 & 4.22 \\
\hline N. ${ }^{\circ}$ de nódulos 1 & 59849.35938 & 1275.17188 & 1290.34063 & 749.0684 & 1.72 & 50.96 & NS \\
\hline N. de nódulos 2 & 57973.75 & 0.79688 & 1253.48333 & 747.50278 & 1.68 & 54.07 & NS \\
\hline $\begin{array}{l}\text { Peso dos } \\
\text { nódulos } 1\end{array}$ & 5.51438 & 140.36672 & 0.10929 & 0.08437 & 1.30 & 39.22 & NS \\
\hline $\begin{array}{l}\text { Peso dos } \\
\text { nódulos } 2\end{array}$ & 7.48984 & 1.28047 & 0.13982 & 0.09138 & 1.53 & 37.86 & NS \\
\hline Altura da planta & 32751.26109 & 0.07813 & 2092.26624 & 27.26446 & $76.74+$ & 9.84 & 7.44 \\
\hline Acamamento & 35.60938 & 5533.875 & 2.12396 & 0.06563 & $32.37+$ & 18.02 & 0.36 \\
\hline Plantas colhidas & 15510.48438 & 6786.17188 & 512.18229 & 145.61285 & $3.52+$ & 8.86 & 17.19 \\
\hline $\begin{array}{l}\text { Vagens por } \\
\text { planta }\end{array}$ & 28139,31859 & 2.875 & 1685.83207 & 59.74652 & $28.22+$ & 16.93 & 11.01 \\
\hline $\begin{array}{l}\text { Peso de } 100 \\
\text { sementes }\end{array}$ & 392.61984 & 0.375 & 18.79182 & 2.41743 & $7.77+$ & 8.21 & 2.21 \\
\hline $\begin{array}{l}\text { Qualidade das } \\
\text { sementes }\end{array}$ & 38.23438 & 894315.85994 & 1.19896 & 0.43229 & $2.77+$ & 22.75 & 0.94 \\
\hline
\end{tabular}

- NS indica que o teste $F$ preliminar para a variedade nŏo foi significativo.

- o sinal $(t)$ depois do valor $F$ indica significancia à probalidade $=0.05$. 
O número de nódulos nas primeiras e se. gunda datas variou de 32 a 82 e 34 a 106 por 10 plantas, respectivamente, enquanto que o peso seco dos nódulos em tais datas variou ontre 0,50 a 1,08 gramas e 0,55 a 1,18 gramas, respectivamente. Todas essas diferenças não foram estatisticamente significativas. Os dados sobre nodulação na ilha da Paciência contrastam notadamente com a excelente nodulação encontrada em Caldeirão (Rahman, 1977). onde o número de nódulos variou entre 104 e 314. Nesta localidade, os pesos dos nódulos variaram entre 1,9 e 3,6 gramas por 10 plantas (médias dos pesos registrados em duas datas) (Rahman, 1977). As razões da nodulação pobre verificada na ilha da Paciência devem ser investigadas.

A maioria das variedades apresentou uma resistência excelente ao acamamento conformo indicam os resultados na Tabela 1. Manaus-1 acamou excessivamente. O comportamento das plantas de Júpiter neste experimento foi muito estranho, com apresentação de vários tipos de distorções morfológicas e acamamento moderado. Já em um experimento vizinho com sementes de Júpiter derivadas do estoque de Caldeirão e plantadas na mesma época, as plantas foram perfeitamente normais e de porte ereto. Não se conhece nenhuma razão €specífica para tal discrepância. Entretanto, é óbvio que se deve a alguma diferença entre os vários canteiros onde essa variedade foi plantada.

Não houve registro de deiscência no presente experimento. A variedade que mais cresceu foi Manaus-1, com uma altura média de $95 \mathrm{~cm}$, enquanto que a mais baixa foi Pickett 71 , com $28 \mathrm{~cm}$ de altura. A Tabela 2 mostra uma correlação positiva altamente significativa entre a altura da planta e o acamamento. A variedade Júpiter cresceu até uma aitura de $66,5 \mathrm{~cm}$ no presente experimento. O número de vagens por planta variou de 119 , no caso da linhagem Manaus-1, a 33, na variedade Pickett 71. A variedade Júpiter produziu uma média de 51 vagens por planta. O peso de 100 sementes de Manaus-1 foi 14,5 gramas, que não foi estatisticamente diferente do verificado para Hill, Woodworth e Pelicano Meihorado, mas diferiu bastante de todas as outras varie. dades. Ransom teve o maior peso de 100 sementes (22 gramas), seguida por Júpiter com 21,3 gramas.

A qualidade das sementes foi consideravelmente reduzida em muitos cultivares devido às condições extremamente desfavoráveis, com chuvas excessivas na época de maturação. A variedade Hill, introduzida pela primeira vez, produziu sementes de excelente qualidade sob as mesmas condições desfavoráveis. Os principais problemas de doença foram o Vírus do Mosáico Comum da Soja (SMV), a Mancha Púrpura (causada pelo fungo Cercospora kikuchü) e a Pústula Bacteriana (causada por Xanthomonas phaseoli var. sojensis). A incidência do Vírus do Mosáico da Soja aumentou consideravelmente neste experimento, em relação à de Caldeirão (Rahman, 1977). Este vírus é reconhecidamente transmitido pela semente, e como as sementes são multiplicadas e os insetos se adaptam à soja recentemente introduzida na Amazônia, é esperado um aumento na transmissão desse vírus. O único método prático de controle desse vírus é o cruzamento com variedades resistentes. As sementes da maioria das variedades apresentaram incidência da Mancha Púrpura. As variedades Pelicano Melhorado, Woodworth, Hill e Júpiter apresentaram boa resistência. Não foram observados problemas com nematóides neste experimento, apesar dos esforços deliberados que foram empregados para encontrá-los.

\section{SUMIMARY}

This work was done in collaboration with the US based international Soy Program (INTSOY). Planting was done late in the varzea cultivation season. Even though this type of experiment is not favorably accepted by the produces, it is good for plant selection. Since the genotypes are under adverse conditions, the most resistant ones will be the ones selected and used in a crop betterment program. "Hill", a newly introduced variety, produced 1,265 Kgs of high quality seed per hectare in 7.5 days, and was found resistent to disease. "Manaus-1" (an INPA strain) produced the best harvest at $2,217 \mathrm{Kgs} / \mathrm{Ha}$, followed by "Jupiter" with $1,373 \mathrm{Kgs} / \mathrm{Ha}$.

Both of these strains should be planted earlier under more favorable conditions. 


\section{BIBLIOGRAFIA CITADA}

NANGJU, D.W.F. K. PLARRE \& AKINPELU, M.A.

1974 - Soybean uniform cultivar trial. Summary of results. IITA/GLIP publication. Received 1977.

Nangju, D.; Rachie, K.O.; Watt, E.E. \& Singh, T.P.

1975 - Cowpea and soybean uniform cultivar trials. IITA/G LIP publication. Received 1977.

RAHMAN, $\mathrm{F}$.

1977 - Introdução e melhoramento de soja na várzea do rio Solimões (Caldeirão, $\mathrm{Ca}$ cau Pirera), no período de 1975 a 1976.

Acta Amazonica, 7(4) : 449-454.

WHIGHAM, D.K.

1976 - International Soybean variety experiment. Second report of results. INTSOY International Agricultural publications. INTSOY series, n. 11.

(Aceito para publicação em 11/03/78) 